\title{
Marx e a Divisão do Lucro Médio em Lucro do Empresário e Juro
}

\author{
Claus M. Germer*
}

\begin{abstract}
Resumo
A concepção da divisão qualitativa do lucro médio em lucro do empresário e juro foi um importante feito teórico de Marx, pois permitiu fundamentar de modo coerente a conceituação do juro como parte da mais-valia, uma vez constituída a taxa média de lucro e sua materialização no lucro médio de cada capital. O objetivo deste artigo é desenvolver e formalizar algumas implicações desta conceituação, em alguns casos à primeira vista desconcertantes. A extensão e a formalização das implicações da divisão do lucro médio, elaboradas por Hilferding, com base nas indicações de Marx, permitiram revelar um novo ângulo do papel do sistema de crédito como potencializador do processo de acumulação. Demonstra-se no artigo que a taxa simples de lucro do empresário perde relevância como indicador de rentabilidade dos capitais, e propõe-se e fundamenta-se a utilização de novo indicador, ao mesmo tempo em que é apontada a relevância de um novo e decisivo fator na análise teórica das taxas de lucro dos capitais individuais.
\end{abstract}

\section{Palavras-Chave}

divisão do lucro médio, lucro do empresário e juro, teoria marxista do juro, lucro e juro em Marx, economia marxista

\section{Marx and the Division of the Average Profit into Interest and Profit of Enterprise}

\begin{abstract}
The concept of the qualitative division of the average profit into profit of enterprise and interest, developed by Marx, was an important theoretical accomplishment, since it made it possible to coherently ground the conceptualization of interest as part of surplus value, once the average profit rate and its materialization in the average profit of each capital have been formed. The aim of this paper is to develop and formalize a few implications of this conceptualization. The extension and the formalization of the implications of the division of the average profit, worked out by Hilferding on the basis of Marx's indications, made it possible to reveal a new dimension of the role of the credit system in enhancing the process of accumulation. The paper shows that the simple rate of profit of enterprise looses relevance as an indicator or the profitability of the individual capitals, and suggests and attempts to ground the use of a new indicator, at the same time as it points to the relevance of a new and decisive element in the theoretical analysis of the profit rates of individual capitals.
\end{abstract}

\section{Keywords}

division of the average profit, profit of enterprise and interest, marxist theory of interest, profit and interest in Marx, marxist economy

\section{JEL Classification}

B14, E11

- Artigo recebido em agosto de 2009 e aceito para publicação em março de 2011 . O autor agradece as valiosas críticas e sugestões do Prof. Francisco Paulo Cipolla e de dois pareceristas anônimos.

* Professor do Programa de Pós-Graduação em Desenvolvimento Econômico da UFPR, Curitiba, PR. Endereço para contato: Universidade Federal do Paraná - Departamento de Economia - Av. Prefeito Lothario Meissner, 632 - Jardim Botânico - CEP: 80210-170 - Curitiba - PR - Email: cmgermer@ ufpr.br - Área da ANPEC - Escolas do Pensamento Econômico, Metodologia e Economia Política 


\section{Introdução}

A concepção da divisão qualitativa do lucro médio em lucro do empresário e juro foi um importante feito teórico de Marx, pois permitiu fundamentar de modo coerente a conceituação do juro como parte da mais-valia, uma vez constituída à taxa média de lucro e sua materialização no lucro médio de cada capital (OC, III/1, p. 277). ${ }^{1}$

O objetivo deste artigo é desenvolver e formalizar algumas implicações desta conceituação, em alguns casos à primeira vista desconcertantes. A fundamentação teórica da divisão do lucro médio em lucro do empresário e juro, exposta por Marx, não pode ser reapresentada neste artigo. Remetem-se os interessados às obras de Marx, nas quais estão expostas: (OC, III/1, cap. 21-24; MARX, 1979, pp. 1469-1534). Não é objetivo deste artigo discutir as definições e os determinantes das taxas médias de lucro e de juros na obra de Marx, mas apenas explorar as implicações da divisão do lucro médio em lucro do empresário e juros. Por outro lado, esta análise tem um inevitável caráter exploratório, uma vez que o tema praticamente não foi abordado por autores marxistas após a obra de Hilferding, de modo que não se dispõe de explorações anteriores que pudessem dar suporte a um avanço maior.

A presente análise é eminentemente abstrata, isto é, examina as relações recíprocas entre a taxa média de lucro e a taxa de juros na sua forma mais simples e com base nos pressupostos teóricos utilizados na exposição de Marx. $\mathrm{O}$ fato de algumas das importantes conclusões alcançadas colidirem com o senso comum, não as invalida antes da verificação empírica metódica, pois é um pressuposto da pesquisa científica que a aparência, refletida pelo senso comum, contradiga frequentemente a essência dos fenômenos. O artigo é de formalização teórica, não de verificação empírica. A complexidade que cerca a determinação da taxa média de lucro e da taxa de juros, nas situações concretas, impede que qualquer dos fatores intervenientes possa ser focalizado neste artigo, mas as indicações de tais fatores e seus efeitos são citadas sempre que cabíveis. Por outro lado, o artigo explora implicações até agora despercebidas de uma parte da teoria de Marx, sem pretender confrontá-las com teorias concorrentes.

\subsection{Juro e Lucro do Empresário}

Segundo a concepção de Marx, a divisão qualitativa do lucro médio em lucro do empresário $^{2}$ e juro implica que se concebe ambos como produtos de duas diferentes

1 Para maior simplicidade da exposição utiliza-se, para referências à obra O Capital, de Marx, por serem numerosas, a abreviação OC seguida do volume em romanos e do tomo em arábicos.

2 A expressão lucro do empresário, utilizada neste artigo, corresponde ao que Marx denominou 'ganho empresarial' (OC, III/1, p. 279). Optou-se por 'lucro do empresário' por parecer mais 
funções do mesmo capital: o juro emanaria da função propriedade do capital, enquanto o lucro do empresário emanaria da sua função produtiva (OC, III/l, p. 280). Perde-se assim completamente a concepção baseada na teoria do valor-trabalho, desde a economia clássica, do juro e do lucro como partes da mais-valia (OC, III/l, p. 281). Esta é a razão pela qual, uma vez consolidada a divisão qualitativa do lucro médio, a contabilidade das empresas registra separadamente os dois rendimentos do seu capital, o lucro do empresário e o juro (ibidem, p. 278, 282; MARX, 1979, p. 1471-2), independentemente das proporções do capital total pertencentes, respectivamente, ao próprio empresário ou obtidas por empréstimo. Isto significa que, quando todo o capital é próprio, o capitalista aufere tanto o lucro do empresário quanto o juro sobre o capital, ou seja, obtém o lucro médio integral. ${ }^{3}$ No caso hipotético do outro extremo, em que todo o capital fosse emprestado, o capitalista funcionante obteria o lucro do empresário, enquanto o juro iria todo para o banco. A divisão do lucro médio pode ser representada do seguinte modo (OC, III/1, p. 290):

$$
\bar{l}=l_{e}+j
$$

em que $\bar{l}$ é o lucro médio, $l_{e}$ o lucro do empresário e $j$ o juro. Tanto o lucro médio quanto o lucro do empresário e o juro resultam da incidência das respectivas taxas, a taxa média de lucro $\left(\bar{l}^{\prime}\right)$, a taxa de lucro do empresário $\left(l_{e}^{\prime}\right)$ e a taxa média de juros $\left(j^{\prime}\right)^{4}$ sobre o mesmo valor-capital total (C):

$$
\bar{l}=\bar{l}^{\prime} C, \quad l_{e}=l_{e}^{\prime} C, \text { e } j=j^{\prime} C
$$

o que implica que $\bar{l}^{\prime}=l_{e}^{\prime}+j^{\prime}$.

A determinação das taxas médias de lucro e de juros não é tema deste artigo, de modo que só pode ser indicada sumariamente. As duas taxas possuem determinantes específicos, ao contrário da taxa de lucro do empresário. A taxa média de lucro

adequado para designar a parte do lucro médio que representa o lucro do capitalista, e porque a opção de Marx não tem qualquer conotação teórica, resultando apenas de uma conveniência semântica, segundo Marx (GERMER, 1995, p. 144). Esta opção está em concordância com a tradução inglesa do livro III de O Capital, que utiliza profit of enterprise. A expressão 'ganho do empresário’ foi adotada, como se verá na última seção do artigo, em outra acepção.

3 "O capitalista que trabalha com capital próprio, assim como o que trabalha com emprestado, reparte seu lucro bruto em juro, que lhe cabe como proprietário, como prestamista de capital a si mesmo, e em ganho empresarial", ambos determinados por leis específicas (OC, III/1, p. 280; no mesmo sentido p. 281, 283).

4 A definição dada por Marx à taxa média de juros encontra-se em OC, III/1, p. 272. Veja-se também Panico, pp. 58ss. 
resulta da concorrência, como tendência contínua, e expressa a relação entre as massas totais da mais-valia e do capital que a gera (OC, III/1, cap. 9 e 10). ${ }^{5}$ A taxa de juros é determinada no mercado monetário, segundo a relação oferta/demanda de capital de empréstimo em termos globais, ${ }^{6}$ e constitui uma parte da taxa média de lucro, como mostrado em (2a). A taxa de lucro do empresário, em contraste resulta, como resíduo, da taxa média de lucro após a dedução da taxa de juros:

$$
l_{e}^{\prime}=\bar{l}^{\prime}-j^{\prime}
$$

Das definições anteriores resulta que, substituindo (2) em (1) obtém-se:

$$
\bar{l}=l_{e}^{\prime} C+j^{\prime} C
$$

A fórmula (3) coloca em evidência o fato de que as taxas de lucro do empresário e de juros incidem sobre o capital total, em parte emprestada ou não, e sejam quais forem as proporções dos capitais próprio e emprestado. Embora isto possa parecer óbvio, há autores que têm entendimento diverso, como Lianos, discutido adiante.

Disto resulta que, uma vez consolidada no senso comum econômico a divisão qualitativa entre o lucro do empresário e o juro, o objetivo do capitalista industrial teria que deixar de ser a obtenção do lucro médio e passaria a ser a obtenção do lucro do empresário. É evidente que, a fim de obter o lucro do empresário, o capitalista deve obter o lucro médio, pois este, uma vez deduzido o juro, proporciona-lhe o lucro do empresário. A divisão do capital total em parte própria e parte emprestada confere uma relevância prática especial à taxa de lucro do empresário, analisada a seguir.

5 A verdadeira taxa média de lucro requer, no entanto, que se acrescente ao denominador o capital comercial existente na economia, segundo exposto no cap. 17 de OC, III/l. Segundo a explicação de Marx, a exposição da formação da taxa média de lucro, feita em capítulo anterior, com base apenas no capital industrial, é necessária "porque o lucro, e, portanto, a taxa geral de lucro, de início tinha de ser desenvolvida necessariamente como equalização dos lucros ou mais-valia realmente produzidos pelos capitais individuais das diferentes esferas da produção" (OC, III/1, p. 215).

6 OC, III/1, cap. 22, especialmente p. 274, e discussão em Panico (pp. 61-81); Itoh e Lapavitsas (p. 72). 


\section{A Taxa de Lucro do Empresário sobre o Capital Próprio - $l_{e p}^{\prime}$}

Hilferding retirou da divisão do lucro médio uma importante implicação sobre a influência do crédito na concorrência: o capitalista que trabalha com parte de capital emprestado obtém uma taxa de lucro do empresário superior à obtida pelos que trabalham apenas com capital próprio, uma vez que obtém o lucro do empresário tanto sobre o capital próprio quanto sobre o emprestado, isto é, obtém o lucro do empresário sobre o capital total, embora seja proprietário de apenas uma parte dele. ${ }^{7}$ Hilferding ilustrou a sua conclusão com um exemplo hipotético simples, supondo uma taxa média de lucro de $30 \%$, que se decompõe em uma taxa de juros de $5 \%$ e uma taxa de lucro do empresário de $25 \%$. Neste caso, um capital próprio de 1 milhão obterá um lucro médio de 300 mil, que será decomposto, na contabilidade da empresa, em 250 mil como lucro do empresário e 50 mil como juros sobre o capital. Como todo o capital é próprio, ambos os rendimentos vão para o próprio capitalista. Em seguida, se o mesmo capitalista puder obter um capital emprestado adicional de 1 milhão, o seu lucro médio sobre o investimento total de 2 milhões será de 600 mil, dos quais 100 mil serão contabilizados como juros sobre o capital total de 2 milhões, e 500 mil como lucro do empresário. O crédito de 1 milhão será devolvido ao banco, acrescido de 50 mil de juros. O lucro do empresário será, portanto, de 500 mil sobre o seu capital próprio de 1 milhão, o que representa uma taxa de lucro do empresário de 50\%, em comparação com a taxa simples de lucro do empresário de $25 \%$, obtida por ele anteriormente, e superior à própria taxa média de lucro (HILFERDING, p. 116).

Isto pode ser formalizado da seguinte maneira: denominemos $\mathrm{C}$ o capital total investido por um capitalista, $C_{p}$ o componente de capital próprio e $C_{e}$ o componente de capital emprestado, ${ }^{8}$ de tal modo que:

$$
C=C_{p}+C_{e}
$$

Como resultado disto, as expressões do lucro do empresário e do juro, em (2), adquirem a seguinte forma:

$$
l_{e}=l_{e}^{\prime}\left(C_{p}+C_{e}\right) \quad \therefore \quad l_{e}=l_{e}^{\prime} C_{p}+l_{e}^{\prime} C_{e}
$$

7 Não se encontrou em Marx referência a este efeito específico, apontado por Hilferding, da divisão lucro do empresário/juro. Na TMV, porém, Marx menciona a possibilidade que tem o capitalista que utiliza crédito, premido pela concorrência, de reduzir os seus preços de venda, sem afetar a rentabilidade do seu capital, o que se esclarecerá adiante (MARX, 1979, p. 1507).

8 O subscrito $e$ é utilizado, neste artigo, em dois sentidos: no sentido de empresário, em $l_{e}$, por exemplo, e no sentido de empréstimo, em $\mathrm{C}_{e}$, por exemplo. Embora inconveniente, esta duplicidade de sentido é inevitável no presente caso. 


$$
j=j^{\prime}\left(C_{p}+C_{e}\right) \quad \therefore \quad j=j^{\prime} C_{p}+j^{\prime} C_{e}
$$

Substituindo $l_{e}$ e $j$ em (1) obtém-se:

$$
\bar{l}=l_{e}^{\prime}\left(C_{p}+C_{e}\right)+j^{\prime}\left(C_{p}+C_{e}\right),
$$

fórmula que pode ser expandida para a sua forma completa:

$$
\bar{l}=\left(l_{e}^{\prime} C_{p}+l_{e}^{\prime} C_{e}\right)+\left(j^{\prime} C_{p}+j^{\prime} C_{e}\right)
$$

em que os parênteses são mantidos apenas para individualizar as frações do lucro do empresário e do juro, respectivamente. Esta fórmula permite explicitar a distribuição dos rendimentos das duas partes do capital:

- $l_{e}^{\prime} C$, decomposto em $l_{e}^{\prime} C_{p}+l_{e}^{\prime} C_{e}$, cabe inteiramente ao capitalista industrial pela função produtiva do capital;

- $j^{\prime} C_{p}$ cabe ao mesmo capitalista pela propriedade da parte $C_{p}$ do capital;

- $j^{\prime} C_{e}$ cabe ao capitalista monetário pela propriedade da parte $C_{e}$ do capital.

Esta fórmula, em notação simplificada e com o rearranjo dos seus membros para melhor explicitar a distribuição dos rendimentos das duas partes do capital, teria a seguinte forma:

$$
\bar{l}=\left(l_{e}+j_{p}\right)+j_{e},
$$

em que $\left(l_{e}+j_{p}\right)$ são os rendimentos que cabem ao capitalista industrial, sendo $j_{p}$ $\left(=j^{\prime} C_{p}\right)$ o juro sobre o capital próprio, e $j_{e}\left(=j^{\prime} C_{e}\right)$ o juro sobre o capital emprestado, que cabe ao capitalista monetário.

Com a inclusão do crédito, a natureza do lucro do empresário, obtido pelo capitalista produtivo, altera-se do ponto de vista formal, uma vez que ele obtém o lucro do 
empresário integralmente $-l_{e}$ - derivado do capital total $\mathrm{C}$, mas possui apenas uma parte deste, a parte $C_{p}$. Para o capitalista produtivo, o lucro do empresário, embora derivado do capital total $\mathrm{C}$, constitui objetivamente um resultado do investimento do seu capital próprio $C_{p}$, ao qual $C_{e}$ se agrega temporariamente. Assim sendo, e considerando a generalização do crédito no capitalismo, o exemplo de Hilferding justifica que se crie um novo conceito de rentabilidade que reflita este importante fenômeno. Este novo conceito é o da taxa de lucro do empresário sobre o capital próprio, ${ }^{9}$ que será representado por $l_{e p}^{\prime}$, com a seguinte fórmula:

$$
l_{e p}^{\prime}=\frac{l_{e}}{C_{p}}
$$

substituindo $l_{e}$ pela sua expressão em (2) obtém-se:

$$
l_{e p}^{\prime}=\frac{l_{e}^{\prime} C}{C_{p}}
$$

expressão na qual o valor total do lucro do empresário $\left(l_{e}\right)$, embora gerado pelo capital total, e não apenas por $\mathrm{C}_{p}$, é relacionado apenas ao capital próprio, ao invés de ao capital total, parte do qual é emprestado.

Lianos, um dos raríssimos autores que, após Hilferding, procurou analisar e formalizar alguns efeitos sobre a concorrência da divisão do lucro médio em lucro do empresário e juro, curiosamente fez uma representação formal errada das taxas de juros e de lucro do empresário. Embora partindo do princípio correto de que $\bar{l}=l_{e}+j$, definiu a taxa de lucro do empresário $\left(l_{e}^{\prime}\right)$ não como o resíduo de $\bar{l}^{\prime}-j^{\prime}$ para a economia como um todo, mas como o produto de $\frac{l_{e}}{C_{p}}$ (convertendo a representação simbólica de Lianos, bastante confusa, para a deste artigo) para o capital individual. No entanto $\frac{l_{e}}{C_{p}}$, segundo o exposto em (4), não é a taxa de lucro do empresário $\left(l_{e}^{\prime}\right)$, mas a taxa de lucro do empresário sobre o capital próprio $\left(l_{e p}^{\prime}\right)$, que o autor, no entanto, não identificou como tal. A verdadeira $l_{e}^{\prime}$ aparece, na equação da taxa média de lucro da formalização de Lianos, como uma expressão sem

9 Hilferding fala em 'lucro sobre seu próprio capital' (p. 117), mas não generaliza esta categoria nem sugere algo como a 'taxa de lucro do empresário sobre o capital próprio'. 
identificação: $\frac{l_{e p}^{\prime} C_{p}}{C} \cdot{ }^{10}$ Finalmente é curioso que, embora tenha citado Hilferding, Lianos não faz qualquer referência ao aspecto do problema que preocupou aquele autor e que se explora neste artigo, que é a diferença de rentabilidade dos capitais individuais resultante da utilização de capital emprestado.

$\mathrm{Na}$ fórmula (4a) surge um importante fator de explicação dos efeitos do crédito sobre a concorrência, que é a proporção do capital próprio no capital total, ${ }^{11}$ proporção esta representada por $p^{\prime}$ :

$$
p^{\prime}=\frac{C_{p}}{C}
$$

Como em (4a) esta proporção está invertida $-\mathrm{C} / \mathrm{C}_{p}-$ a fórmula pode ser reescrita como:

$$
l_{e p}^{\prime}=\frac{l_{e}^{\prime}}{p^{\prime}}
$$

o que significa que a taxa de lucro do empresário sobre o capital próprio depende diretamente da taxa de lucro do empresário e inversamente da proporção do capital próprio sobre o capital total. A influência da taxa de juros fica mais clara se $l_{e}^{\prime}$ for substituído, em (5), pela sua expressão em (2b):

10 Isto se demonstra facilmente substituindo nesta fórmula a expressão de $l_{e p}^{\prime}$ em (4), do que se obtém $\frac{l_{e}}{C}=l_{e}^{\prime}$. Como Lianos representa $l_{e}^{\prime}$ erradamente, pelo que na realidade é $l_{e p}^{\prime}$, que não identificou como tal, ficou sem categoria teórica correspondente a $1_{e} / C$. O quanto Lianos afasta-se do entendimento de Marx, revela a sua conclusão que, quando as taxas de juros e de lucro do empresário são iguais, elas também são iguais à taxa média de lucro, o que se choca frontalmente com a concepção de Marx, de que esta última taxa constitui a soma das duas primeiras, como em (2a).

11 A proporção de $C_{p}$ e $C_{e}$ no capital total apresenta grande complexidade em condições concretas. $\mathrm{Na}$ literatura não marxista atual estas proporções dão origem ao que se denomina estrutura do capital, que é objeto de acentuada controvérsia. Na literatura estadunidense, que domina a análise do tema, esta toma como base a sociedade anônima e gira, em grande parte, em torno do grau de validade do chamado teorema Modigliani-Miller ou MM (ver, por exemplo, ROSS et al., parte IV, e FRIEDMAN, p. 280). Com base na sociedade anônima, $C_{p}$ é representado pelas ações e $\mathrm{C}_{e}$ pelas dívidas ou 'capital de terceiros' (ROSS et al., p. 26-7 e cap. 15; e GITMAN, p. 286 e 468). Na análise marxista aqui adotada, a difusão do capital acionário tem também efeitos muito importantes que não podem, no entanto, ser abordados neste artigo e não afetam o problema analisado, uma vez que a sociedade anônima altera a estrutura jurídica do capital e a distribuição do lucro médio, mas não a estrutura técnica do capital nem a geração do lucro médio (OC, III/2, p. 11-13). 


$$
l_{e p}^{\prime}=\frac{\overline{l^{\prime}}-j^{\prime}}{p^{\prime}}
$$

No exemplo de Hilferding, no qual $l_{e}^{\prime}=0,25, \mathrm{C}=2$ milhões e $\mathrm{C}_{p}=1$ milhão, sendo, portanto, $p^{\prime}=0,5$, o cálculo seria o seguinte:

seguindo a fórmula (4a): $l_{e p}^{\prime}=(0,25.2) / 1=0,5$ ou $50 \%$;

seguindo a fórmula (5): $l_{e p}^{\prime}=0,25 / 0,5=0,5$ ou $50 \%$.

Desta elaboração de Hilferding, baseada na proposição teórica de Marx sobre a divisão do lucro médio, retira-se uma conclusão desconcertante, mas teoricamente consistente: a de que, diante de um aumento da taxa de juros, não é vantajoso que o capitalista industrial reduza o seu recurso ao crédito. Isto parece colidir frontalmente com o senso comum econômico, segundo o qual o aumento da taxa de juros resulta em redução da demanda de crédito, mas a sua consistência teórica pode ser demonstrada facilmente. Vejamos inicialmente o que ocorre, utilizando ainda o exemplo de Hilferding, caso a taxa de juros se eleve de $5 \%$ para $15 \%$, mantendo a hipótese de uma taxa média de lucro de 30\%. Esta elevação da taxa de juros teria como contrapartida a redução da taxa de lucro do empresário $\left(l_{e}^{\prime}\right)$ de $25 \%$ para $15 \%$.

Vimos que, ao tomar 1 milhão em complemento ao seu capital próprio de 1 milhão, com $j^{\prime}=5 \%$, o capitalista obteve $l_{e p}^{\prime}=50 \%$. Com o aumento de $j^{\prime}$ para $15 \%$, aplicando a fórmula (5): $l_{e p}^{\prime}=0,15 / 0,5=0,3$ ou $30 \%$. Portanto, a taxa de lucro do empresário sobre o capital próprio caiu de $50 \%$ para $30 \%$.

Suponhamos que, diante da elevação da taxa de juros, o capitalista reaja reduzindo o empréstimo bancário, porém mantendo o valor do investimento total. ${ }^{12}$ Suponhamos que o capital de empréstimo de 1 milhão seja reduzido para $500 \mathrm{mil}$

12 Pode-se questionar esta hipótese sob o argumento de que o capitalista não teria capital próprio para substituir parte do capital até então emprestado, pois por que tomaria empréstimo se tivesse capital próprio? Mas a reação de reduzir a escala da produção também é duvidosa, uma vez que a elevação da taxa de juros, se excetuarmos o momento de auge e crise, acompanha o crescente aquecimento da economia, fase na qual a redução da escala da produção é uma medida que dificilmente se pode justificar, exceto em casos de extrema gravidade da situação de uma empresa, pois implicaria perda de mercado e, consequentemente, a situação da empresa pioraria ainda mais. Por outro lado, a manutenção do mesmo nível da atividade ao mesmo tempo em que o recurso ao crédito é reduzido, pode ser explicada pela liquidação de outros ativos e a concentração dos investimentos na atividade principal. 
e o capital próprio aumentado para 1,5 milhões, de modo que $p^{\prime}$ eleva-se a 0,75 e $C$ mantém-se inalterado em 2 milhões. O resultado seria $l_{e p}^{\prime}=0,15 / 0,75=0,2$.

Portanto, com a redução do capital emprestado, a taxa de lucro do empresário sobre o capital próprio caiu de $30 \%$ para 20\%. Isto significa, como afirmado acima, que a tentativa de fugir do custo financeiro mais elevado, reduzindo o capital de empréstimo, deteriora ainda mais a taxa de lucro. ${ }^{13}$

Este surpreendente resultado sugere a relevância de se examinar de modo mais sistemático a relação entre $l_{e p}^{\prime}$ e $l_{e}^{\prime}$ e os determinantes das flutuações de ambos.

\section{Relação entre - $l_{e p}^{\prime}$ e $l_{e}^{\prime}$}

A simulação com base na ilustração de Hilferding mostrou que, com o aumento da taxa de juros, $l_{e p}^{\prime}$ reduziu-se. Deve-se notar, no entanto, que $l_{e p}^{\prime}$, embora reduzida de $50 \%$ para $30 \%$, permanece acima da taxa simples de lucro do empresário ( $l_{e}^{\prime}$ $=15 \%$ ). A fórmula (4a) mostra que este resultado não é casual, permitindo uma importante generalização sobre a relação entre $l_{e p}^{\prime}$ e $l_{e}^{\prime}$. Desta fórmula deduz-se de imediato a seguinte importante regra: nos investimentos em que uma parte do capital é emprestada, sempre se verificará que $l_{e p}^{\prime}>l_{e}^{\prime}$, isto é, a taxa de lucro do empresário sobre o capital próprio será sempre superior à taxa simples de lucro do empresário, obtida pelo capitalista industrial que não recorre a crédito algum. Isto decorre do fato de que $l_{e p}^{\prime}$ resulta da multiplicação de $l_{e}^{\prime}$ por $\mathrm{C} / \mathrm{C}_{p}$, que será sempre superior a 1 , uma vez que, sendo $C_{p}$ um componente de $C$, segue-se que sempre $C>$ $\mathrm{C}_{p}$, e consequentemente $\left.\frac{C}{C_{p}}\right\rangle 1$. Quando $\mathrm{C}_{p}=\mathrm{C}$ (isto é, quando todo o capital é próprio), $l_{e p}^{\prime}=l_{e}^{\prime}$, o que significa que $l_{e}^{\prime}$ é o valor mínimo de $l_{e p}^{\prime}$.

Isto pode também ser demonstrado de outro modo. Expandindo o numerador da fórmula (4a), obtém-se:

13 Note-se que $l_{e p}^{\prime}$ depende inversamente da taxa de juros, de modo que, aumentando esta, ceteris paribus, caem tanto $l_{e}^{\prime}$ como $l_{e p}^{\prime}$. O que se procura mostrar aqui é que a reação de reduzir o recurso ao crédito causaria queda ainda maior de $l_{e p}^{\prime}$, nada alterando, obviamente, em $l_{e}^{\prime}$. Note-se também que, na fase ascendente do ciclo, a elevação da taxa de juros é normal e seria irracional que o capitalista reduzisse por este motivo o crédito, por pelo menos duas razões: primeiro, a taxa média de lucro pode estar em ascensão também - o que se aborda na seção 7 - e o que compensaria, pelo menos em parte, o efeito da elevação da taxa de juros sobre $l_{e}^{\prime}$; segundo, a elevação da demanda, abstraídas as exceções, associada à expansão econômica, requer expansão e não redução do nível de atividade de cada empresa. Finalmente, se a taxa de juros é determinada pela relação entre a oferta e a demanda de capital de empréstimo, a sua elevação indica que há, em termos agregados, não só demanda de crédito, como também demanda superior à oferta, que é precisamente o fator determinante da elevação da taxa de juros (OC, III/l, p. 322). 


$$
l_{e p}^{\prime}=\frac{l_{e}^{\prime} C_{p}+l_{e}^{\prime} C_{e}}{C_{p}}, \text { ou } l_{e p}^{\prime}=\frac{l_{e}^{\prime} C_{p}}{C_{p}}+\frac{l_{e}^{\prime} C_{e}}{C_{p}}
$$

Nesta fórmula, $l_{e p}^{\prime}$ reduz-se a $l_{e}^{\prime}$ caso $C_{e}$ seja nulo, isto é, caso o capitalista não recorra ao crédito, de modo que $\frac{l_{e}^{\prime} C_{e}}{C_{p}}$ será nulo. Portanto, o excedente de $l_{e p}^{\prime}$ sobre $l_{e}^{\prime}$ consiste na fração de $l_{e}$ representada por $l_{e}^{\prime} C_{e}$, obtida pelo tomador do crédito sobre o capital emprestado.

Isto significa que, com a generalização do crédito, ${ }^{14}$ a taxa simples de lucro do empresário torna-se irrelevante como medida da rentabilidade dos capitais, exceto como indicador do limite mínimo de $l_{e p}^{\prime}$. Este resultado é significativo porque indica que, com crédito bancário generalizado, a eventual igualação da taxa de lucro do empresário $\left(l_{e}^{\prime}\right)$ à taxa de juros não implica que os capitalistas ficarão indiferentes entre o investimento industrial e a aplicação financeira, uma vez que, com a utilização de crédito, sempre $l_{e p}^{\prime}>l_{e}^{\prime}$. Também não implica, pelo mesmo motivo, que o investimento produtivo será interrompido assim que $l_{e}^{\prime}<j$ '. Se a EMK, proposta por Keynes, corresponder a $l_{e}^{\prime}$, a conclusão de Keynes indicando a indiferença entre as duas aplicações quando a EMK iguala a taxa de juros é inválida, de modo que o investimento produtivo prosseguiria ainda que $l_{e}^{\prime}$ caísse abaixo de $j^{\prime}$. Ainda mais, como $l_{e p}^{\prime}$ é sempre maior que $l_{e}^{\prime}$, segue-se que o confronto relevante da taxa de juros não é com $l_{e}^{\prime}$, mas com $l_{e p}^{\prime}$.

A exposição até este ponto permite apontar os equívocos provocados pela observação desatenta dos fenômenos econômicos. No caso da divisão do lucro médio observa-se uma sucessão deles. O primeiro equívoco é supor que, como consequência desta divisão, a medida da rentabilidade do capital industrial deixa de ser a taxa média de lucro, substituída pela taxa de lucro do empresário. Há um duplo equívoco nesta interpretação: o primeiro é considerar que a taxa de lucro do empresário seja uma medida de rentabilidade do capital industrial; o outro, que a taxa de lucro do empresário substitua a taxa média de lucro como tal medida. A taxa média de lucro não pode ser substituída como medida da rentabilidade do capital industrial, porque a taxa média de lucro é determinada por condições estruturais do processo global de reprodução, não podendo, portanto, ser afetada por mudanças na distribuição do lucro médio. Diante do exposto, a taxa média de lucro continua

14 “... a maioria dos capitalistas industriais, ainda que em proporções numéricas diferentes, trabalha com capital próprio e emprestado..." (OC, III/1, p. 281). 
sendo a medida correta da rentabilidade do capital industrial. Por outro lado, a taxa de lucro do empresário não é uma medida da rentabilidade do capital industrial, mas da função do capitalista industrial. Ao se introduzir na análise a distribuição do lucro médio, deve-se necessariamente levar em conta a diferenciação das medidas de rentabilidade dos diversos beneficiários da distribuição, entre estes o próprio capitalista industrial.

É necessário, no presente caso, distinguir entre o capital industrial e o capitalista industrial. O capital industrial é a unidade técnica e econômica de produção, ao passo que o capitalista industrial é o operador do capital industrial, que com a emergência do crédito passa a ser proprietário de apenas uma parte do capital industrial. Portanto, como consequência da divisão do lucro médio surge uma divisão da medida da rentabilidade: à medida da rentabilidade do capital industrial é preciso acrescentar uma medida da rentabilidade obtida pelo capitalista industrial. À primeira vista esta última medida é a taxa de lucro do empresário. Isto, no entanto, também é um equívoco, justificado a seguir.

Embora a divisão do lucro médio coloque em evidência a taxa de lucro do empresário como medida da rentabilidade obtida pelos capitalistas, a medida real passa a ser a taxa de lucro do empresário sobre o capital próprio. Os leitores de O Capital geralmente deixam-se iludir pelo efeito imediato da divisão do lucro médio, que é o de aparentemente rebaixar a rentabilidade do capital industrial, da taxa média de lucro para a taxa de lucro do empresário, uma vez que uma parte do lucro médio deve ser entregue ao emprestador na forma de juros.

Deixa-se de observar, por um lado, como já notado, que a rentabilidade do capital industrial não pode ser alterada por uma mudança na distribuição do lucro médio e, por outro lado, que embora parte do lucro médio vá para o capital de empréstimo, o capitalista industrial apropria-se, em contrapartida, da fração do lucro do empresário produzida pelo capital emprestado, ao mesmo tempo em que reduz a sua participação no investimento, do que resulta que, ao contrário do que parece, a taxa de lucro do empresário (neste caso o capitalista industrial) sobre o seu capital aumenta ao invés de diminuir após a divisão do lucro médio. Portanto, a medida relevante da rentabilidade obtida pelo capitalista industrial passa a ser a taxa de lucro do empresário sobre o capital próprio. Torna-se evidente, portanto, que embora a divisão do lucro médio desvie uma parte deste para o capital de empréstimo, aumenta a taxa que cabe ao capitalista industrial. Ou seja, através do crédito os capitalistas industriais aumentam a rentabilidade do seu capital ao invés de reduzi-la.

Duas conclusões opostas possíveis emanam desta exposição. Por um lado, parece que se deveria deduzir que o volume do capital industrial, em termos globais, de- 
veria reduzir-se em relação ao capital portador de juros, uma vez que cada capitalista industrial reduz a sua participação no seu próprio capital, enquanto aumenta a do capital portador de juros. Por outro lado, ao mesmo tempo parece que se deveria esperar o contrário, pois se a rentabilidade dos capitalistas industriais - isto é, $l_{e p}^{\prime}$ - aumenta com a emergência e difusão do crédito, os capitais deveriam migrar para os investimentos industriais. No entanto, se uma parte substancial do capital social, convertida em capital portador de juros, mantém-se nesta condição mesmo obtendo uma taxa de juros inferior à taxa de lucro do empresário sobre o capital próprio, isto indica que outros fatores, que emergirão em análises de situações concretas, afetam a distribuição dos capitais entre setores da economia. A relevância da presente análise consiste em identificar uma importante causa adicional, até agora não percebida, inerente à essência do processo de distribuição do lucro médio.

A análise desses fatores não é tema deste artigo, mas deve-se indicar que a dimensão do capital portador de juros é determinada, em grande parte, endogenamente, pela fração do capital total que deve obrigatoriamente permanecer ociosa, como causa ou efeito do processo de reprodução do capital industrial. Esta parte do capital industrial em princípio não geraria rendimento algum para o capitalista industrial, uma vez que deve permanecer ociosa por imposição das características do processo de reprodução em cada caso (HILFERDING, cap. 4). Consequentemente, a taxa de rendimento que possa ser obtida da sua aplicação temporária não deve ser comparada com a taxa de lucro do empresário, mas com o rendimento nulo decorrente da sua ociosidade forçada.

\section{A Taxa de Lucro do Empresário sobre o Capital Próprio, Alavanca da Acumulação}

As implicações da divisão do lucro médio, até aqui examinadas pelo ângulo negativo das possibilidades de reação dos capitalistas individuais a elevações da taxa de juros, devem ser analisadas principalmente pelo ângulo positivo, que foram enfatizadas por Hilferding. Hilferding mostrou que a difusão do crédito fornece aos capitalistas que a ele recorrem uma nova arma na concorrência: uma vez que obtém uma taxa de lucro do empresário sobre o capital próprio superior à simples taxa de lucro do empresário, obtida pelos capitalistas que não recorrem ao crédito, os que a ele recorrem podem reduzir seus preços de venda abaixo do preço de produção, a fim de capturar fatias de mercado dos concorrentes (HILFERDING, p. 117). Marx fez idêntica referência na TMV, como mencionado na nota de rodapé 7: 


\begin{abstract}
"Se, por exemplo, a taxa de juros cair e as condições de mercado determinarem a redução [dos preços - CMG] das mercadorias abaixo dos seus preços de custo, o industrial [que utiliza crédito - CMG] pode reduzir o preço da mercadoria sem reduzir a taxa do lucro industrial; ele pode mesmo reduzi-lo [o preço] e obter um lucro industrial maior, o que, no entanto, representaria para aquele que só trabalha com capital próprio, uma queda da taxa de lucro; do lucro bruto" (MARX, 1979, p. 1507). ${ }^{15}$
\end{abstract}

Os elementos expostos até aqui permitem compreender este argumento de Marx e, por extensão, o de Hilferding. Tomando como referência a fórmula (6), o argumento de Marx, seguido por Hilferding, baseia-se no fato de que $l_{e}^{\prime} C_{e}$ é o excedente sobre $l_{e}$ (lucro industrial, na citação acima), que o capitalista obtém sobre o seu capital próprio, graças ao crédito.

Como se demonstrou acima, $l_{e p}^{\prime}$ é sempre maior que $l_{e}^{\prime}$, graças a $l_{e}^{\prime} C_{e}$. Se ele não recorresse ao crédito, $l_{e}^{\prime} C_{e}$ seria nulo e a sua taxa de lucro do empresário seria a taxa simples: $\frac{l_{e}^{\prime} C_{p}}{C_{p}}$, que corresponde à fórmula geral $\frac{l_{e}^{\prime} C}{C}$, uma vez que $C_{p}$ neste caso é o capital total C. Sendo assim, o capitalista que recorre ao crédito pode, premido pela concorrência ou diante de uma crise, reduzir seus preços sacrificando $l_{e}^{\prime} C_{e}$ no todo ou em parte, sem afetar a sua taxa simples de lucro sobre o capital próprio $^{16}$ e mesmo sem sacrificar totalmente o excedente sobre o simples lucro do empresário. Por outro lado, a vantagem advinda da queda da taxa de juros, mencionada no início da citação, deve-se ao aumento de $l_{e}^{\prime}$ daí decorrente, em consequência do que também aumenta $l_{e p}^{\prime}$, proporcionando ao capitalista que trabalha com crédito maior margem para ameaçar concorrentes com reduções de preços. Neste caso o capitalista poderia mesmo obter o que Marx denomina "um lucro industrial

15 Nesta citação da obra Teorias da mais-valia, as categorias derivadas do lucro médio ainda não haviam recebido suas denominações definitivas. Assim, o 'preço de custo' corresponde ao preço de produção (MARX, 1979, p. 1477, 1482 e PASSIM), o lucro industrial e sua taxa correspondem ao lucro do empresário e sua taxa (idem, p. 1471, 1490 e PASSIM), e a taxa de lucro e o lucro bruto correspondem à taxa média de lucro e ao lucro médio (idem, p. 1454,1482 e PASSIM).

16 "Ele sacrifica o lucro do empresário sobre o capital alheio, não o lucro sobre o capital próprio" (HILFERDING, p. 117). 
maior" do que antes, desde que a redução de preços seja menor que o aumento de $l_{e}$ decorrente da redução da taxa de juros. Enquanto isso, o capitalista que só trabalha com capital próprio, cujo 'lucro bruto' corresponde ao lucro médio, sofreria uma redução deste, isto é, do que para ele é o lucro 'normal', caso fosse forçado a reduzir o seu preço de venda.

Deve-se considerar, no entanto, que a redução de preços mencionada apresenta aspectos contraditórios. A possibilidade de reduzir preços, mencionada por Marx, constitui ou uma reação defensiva diante de imposições do mercado ou o aproveitamento da margem de manobra ocasional proporcionada pela redução da taxa de juros, possíveis somente aos capitalistas que trabalham com crédito. Mas ambas as situações pressupõem que a composição orgânica do capital e a produtividade do trabalho permanecem inalteradas, ou seja, não há avanço qualitativo do capital. Além disso, a redução de preços também reduz a rentabilidade anterior do capital, mesmo preservando no mínimo o lucro do empresário, não podendo, portanto, ser considerada o efeito mais dinâmico proporcionado pelo crédito aos capitalistas que o utilizam.

O efeito mais dinâmico, que não passou despercebido a Hilferding, consiste na possibilidade que a rentabilidade mais elevada proporciona, de mais rápida elevação das escalas de produção e, consequentemente, de aceleração do progresso técnico e do aumento da produtividade do trabalho, resultando em novos aumentos de rentabilidade devidos à redução de custos unitários que permitem reduções competitivas de preços e captura de fatias de mercado adicionais (HILFERDING, p. 116-7). Neste caso as reduções de preços não são meramente reativas, mas ofensivas, e não reduzem a rentabilidade, mas a aumentam (OC, I/1, cap. 10). Em contrapartida, na medida em que os aumentos de escala são acompanhados pela elevação da composição orgânica média do capital, contribuirão para a tendência de queda da taxa média de lucro. Sendo assim, este aspecto do crédito deve ser acrescentado à centralização do capital, analisado por Marx na exposição da lei geral da acumulação capitalista, como um dos grandes efeitos da expansão do sistema de crédito (OC, I/2, cap. 23).

O desenvolvimento de Hilferding abre um novo ângulo no que diz respeito ao extraordinário papel do crédito no processo de acumulação. Hilferding tem grande mérito por apoiar-se nas indicações mais gerais de Marx, sem se limitar a apenas repeti-las para, com base nelas, apontar implicações mais concretas, de grande relevância, que aprofundam a compreensão dos fenômenos do capitalismo. Da perspectiva aberta por Hilferding, explorando mais ampla e originalmente as indicações de Marx, o crédito deixa de apresentar-se como simples meio de cobrir insuficiências momentâneas de capital próprio, para ser encarado como elemento essencial à po- 
tencialização da força expansiva dos capitais individuais: "a elevação do lucro do empresário dos capitalistas individuais os incentiva ao uso cada vez mais intensivo do crédito" (HILFERDING, p. 117).

Em outras palavras, Hilferding desenvolve alguns aspectos cruciais que mostram objetivamente como o crédito funciona como verdadeira alavanca da acumulação. A formalização e a extensão desta elaboração de Hilferding, neste artigo, conferem uma dimensão nova e mais contundente à caracterização do papel do sistema de crédito por Marx: "... com a produção capitalista constitui-se uma potência inteiramente nova, o sistema de crédito, que... logo se torna uma nova e temível arma na luta da concorrência e finalmente se transforma em enorme mecanismo social para a centralização dos capitais" (OC, I/2, p. 197).$^{17}$

O crédito pode deixar, assim, de ser encarado como um fenômeno eventual a complementar a acumulação de capitalistas individuais, devendo ser encarado como instrumento central da acumulação, especialmente da centralização dos capitais. Em outras palavras, o capital de empréstimo converte-se em pilar essencial das estratégias de acumulação dos capitais individuais. Nas eloquentes palavras de Hilferding, "deste modo o capital próprio, utilizado pelos capitalistas produtivos, torna-se para eles apenas a base de um investimento que, com a ajuda de capital alheio, é estendido muito além do capital próprio" (HILFERDING, p. 117). Através do crédito, os capitalistas individuais escapam da limitação da taxa média de lucro, pois podem elevar as suas taxas de lucro individuais $\left(l_{e p}^{\prime}\right)$ sem que a taxa média de lucro se altere.

A generalização do crédito e a centralização do capital implicam que o aspecto relevante da concorrência abrange não só a relação entre empresas que utilizam e empresas que não utilizam crédito, mas também a relação entre as que o utilizam em maior e as que o utilizam em menor proporção, respectivamente, o que torna o grau de acesso ao crédito um fator relevante na concorrência. A diferença de graus de acesso, apontada nas seções seguintes, por outro lado, indica não se poder sugerir a existência de uma tendência de formação de algo como uma taxa média de lucro do empresário sobre o capital próprio, que funcionaria como um substituto da taxa média de lucro.

A análise teórica aqui desenvolvida indica que a elevação do grau de endividamento constitui uma tendência dos capitais no processo de acumulação. Em uma análise menos abstrata, porém, constata-se a presença de fatores amortecedores desta ten-

17 Ao lado deste efeito dinâmico do crédito, Marx também insistiu nos seus efeitos como gerador de 'superespeculação' e como causador e/ou intensificador das crises periódicas (por exemplo, OC, III/1, p. 335). 
dência. Ross et al. mostram, de outro ponto de vista teórico e no contexto particular da economia dos EUA, a presença desta contradição: "sempre se pode aumentar o valor da empresa [refere-se à sociedade anônima - CMG] elevando o endividamento; o que quer dizer que as empresas deveriam usar o máximo possível de capital de terceiros. $^{18}$ Isto é incompatível com a realidade, pois as empresas geralmente usam níveis de endividamento apenas moderados" (ROSS et al., p. 325). Mas os autores prendem-se ao caso particular dos EUA, como mostram os dados apresentados por eles mesmos, mais adiante, que indicam que a moderação mencionada deve-se a fatores específicos da economia estadunidense, pois o grau médio de endividamento das empresas de outros países era significativamente maior (ibidem, p. 341).

Por outro lado, os mesmos autores revelam, com ironia, a inexistência de uma teoria consistente sobre a estrutura do capital:

"As teorias da estrutura de capital se encontram entre as mais elegantes e sofisticadas na área de finanças. (...) Entretanto, as aplicações práticas da teoria não são completamente satisfatórias. (...) Não há fórmula exata disponível para avaliar o quociente ótimo entre capital de terceiros e capital próprio. Por causa disso, recorremos a evidências encontradas na prática" (ibidem, p. 340, itálicos acrescentados).

A limitação à evidência prática explica as inúmeras constatações contraditórias dispersas ao longo da obra e o caráter inconclusivo do seu enfoque, levando a afirmações desalentadas como "não podemos afirmar que mais dívida seja melhor que menos dívida" (ibidem, p. 342).

\section{Determinantes das Flutuações de $l_{e p}^{\prime}$}

Segundo a fórmula (5), $l_{e p}^{\prime}$ depende da taxa de lucro do empresário $\left(l_{e}^{\prime}\right)$ e do grau de endividamento $\left(p^{\prime}\right)$. No entanto, $l_{e}^{\prime}$ não é determinado independentemente, sendo apenas um resíduo, segundo a fórmula (2b), de modo que a variação de $l_{e}^{\prime}$, dada a taxa média de lucro, reflete exatamente a variação de $j^{\prime}$ em sentido

18 Outras evidências nesta direção encontram-se na mesma obra, como por exemplo: "o custo do capital frequentemente cai com o uso de capital de terceiros" (ROSS et al., p. 355). 
contrário. ${ }^{19}$ Sendo assim, é mais correto dizer que $l_{e p}^{\prime}$ depende da taxa de juros e do grau de endividamento. Como consequência disto, ao dizer que $l_{e p}^{\prime}$ depende dire tamente de $l_{e}^{\prime}$, entende-se que depende inversamente de $j^{\prime}$. O grau de endividamento, por outro lado, é medido pelo seu inverso, a proporção de capital próprio que é $p^{\prime}$. Como $p^{\prime}$ está no denominador, segue-se que $l_{e p}^{\prime}$ depende inversamente de $p^{\prime}$, o que significa que depende diretamente do grau de endividamento, ou seja, $l_{e p}^{\prime}$ aumenta quando o grau de endividamento aumenta e vice-versa. Portanto, $l_{e p}^{\prime}$ depende inversamente da taxa de juros e diretamente do grau de endividamento. ${ }^{20}$

Ou seja, quando a taxa de juros aumenta ou diminui, com $p^{\prime}$ inalterado, $l_{e p}^{\prime}$ diminui ou aumenta, respectivamente, e, de modo análogo, quando $p^{\prime}$ aumenta ou diminui, com $j^{\prime}$ inalterado, $l_{e p}^{\prime}$ diminui ou aumenta, respectivamente.

O efeito da variação de $j^{\prime}$ sobre $l_{e p}^{\prime}$, mantido o valor de $p^{\prime}$, é explicado pela fórmula (4a): com o aumento da taxa de juros, caem $l_{e}^{\prime}$ e consequentemente o numerador $l_{e}^{\prime} C$, enquanto o denominador $C_{p}$ permanece inalterado, de modo que $l_{e p}^{\prime}$ cai.

A redução da taxa de juros tem resultado oposto, isto é, provoca o aumento de $l_{e p}^{\prime}$. O efeito da variação do grau de endividamento - $p^{\prime}-$, mantido o valor de $j^{\prime}$, é evidenciado em (5). Neste caso o numerador $l_{e}^{\prime}$ permanece inalterado, enquanto $p^{\prime}$, que está no denominador, altera-se. Portanto, quando o grau de endividamento aumenta (isto é, $p^{\prime}$ diminui), $l_{e p}^{\prime}$ aumenta, e vice-versa. Em (4a), a razão deste resultado é mais evidente: o numerador $l_{e}^{\prime} C$ mantém-se inalterado, enquanto o denominador $C_{p}$ aumenta ou diminui, provocando redução ou aumento de $l_{e p}^{\prime}$, respectivamente.

Mas as variações da taxa de juros e do grau de endividamento são determinadas em níveis diferentes. A taxa de juros, assim como a sua variação, são determinadas no mercado monetário, portanto são dadas para o capitalista individual. O grau de endividamento, ao contrário, pode ser alterado por ele dentro de certos limites. Como já se mostrou, utilizando a ilustração de Hilferding, a reação de um capitalista à queda de $l_{e p}^{\prime}$ devido ao aumento da taxa de juros, de reduzir o apelo ao

19 "Se o lucro bruto é igual ao lucro médio, então a grandeza desse ganho empresarial é determinada exclusivamente pela taxa de juros" (OC, III/1, p. 279).

20 Consequentemente, as referências deste artigo ao grau de endividamento devem ser entendidas como medidas pelo seu inverso, $p^{\prime}$. 
crédito, conduziria a uma queda ainda maior de $l_{e p}^{\prime}$. A reação indicada pela formalização aqui exposta seria, ao contrário, a elevação do grau de endividamento, ou seja, a redução de $p^{\prime}$. Isto decorre da lógica da divisão juro/lucro do empresário: algebricamente este resultado é irrefutável, uma vez que $p^{\prime}$, denominador da fórmula (5), diminui; ou, na fórmula (4a), ao aumentar o capital emprestado, diminui o capital próprio, no denominador.

Esta conclusão também é coerente do ponto de vista econômico, o que pode ser mostrado mais claramente através da decomposição do numerador de (4a), exposta na fórmula (6). Segundo esta fórmula, todo o lucro do empresário, que comparece no numerador, é apropriado pelo capitalista industrial, mas o responsável pela superioridade de $l_{e p}^{\prime}$ sobre $l_{e}^{\prime}$ é, como já assinalado, a fração $l_{e}^{\prime} C_{e}$, o lucro do empresário obtido por ele sobre o capital emprestado $C_{e}$. Esta fração aumenta à medida que $\mathrm{C}_{e}$ aumenta, dada a taxa de juros. Além disso, à medida que $\mathrm{C}_{e}$ aumenta, o capital próprio, base do cálculo da rentabilidade, no denominador, contrai-se. Consequentemente, dado $l_{e}^{\prime}, l_{e p}^{\prime}$ aumenta necessariamente à medida que a proporção de $\mathrm{C}_{p}$ diminui.

Disto parece poder deduzir-se, também logicamente, que a existência de uma tendência crescente da taxa de juros não deveria ser seguida pela redução da demanda de $\mathrm{C}_{e}$. Do ponto de vista lógico, parece que se deveria antes esperar um aumento da demanda de $\mathrm{C}_{e}$, portanto uma redução de $p^{\prime}$. Alguns condicionantes desta tendência são apontados adiante, mas este problema teria de ser analisado levando em conta outras circunstâncias que cercam o processo global de acumulação.

No entanto, há limites tanto para a redução de p', ou seja, para o aumento do grau de endividamento, como para a elevação da taxa de juros. É óbvio que não é o limite mínimo de $p^{\prime}$ que estabelece o limite máximo de $j^{\prime}$. O limite máximo da taxa de uros é a taxa média de lucro. Atingido este limite, $l_{e}$ e $l_{e p}^{\prime}$ seriam nulos. O limite ao aumento da taxa de endividamento é determinado, entre outros fatores, pelos critérios de segurança do sistema de crédito. A posse de um mínimo de capital próprio é uma condição essencial da garantia dos empréstimos (KALECKI, p. 133). ${ }^{21}$

21 Por esta e outras razões já apontadas, a elevação do grau de endividamento está geralmente associada à elevação diferenciada das taxas de juros para tomadores mais endividados, como expressão da elevação do risco bancário ou, nos termos de Minsky, do aumento da fragilidade financeira da empresa. Este diferencial de juros pode funcionar, portanto, como fator amortecedor do aumento de p' (ver, no mesmo sentido, MAYER et al., p. 32). Ross et al., analisando a estrutura financeira das sociedades anônimas e destacando o caráter abstrato do teorema de Modigliani-Miller, apontam outros fatores amortecedores, que consideram essenciais, tais como o custo crescente de falência e os efeitos da política tributária dos EUA (ROSS et al., cap.16). De modo mais geral, na análise concreta, o custo do crédito envolve não só a taxa de juros, mas também outros 
A partir desse ponto, novas elevações de $j^{\prime}$ não poderiam ser compensadas por reduções de $p^{\prime}$, portanto causariam necessariamente queda tanto de $l_{e}^{\prime}$ como de $l_{e p}^{\prime}$. Considerando (5), o limite mínimo de $p^{\prime}$ constitui o limite às possibilidades de reação do capital industrial às elevações de $j^{\prime}$, via aumento do grau de endividamento. Mas $j^{\prime}$ pode elevar-se acima de $l_{e p}^{\prime}$ antes que o limite mínimo de $p^{\prime}$ seja atingido. Neste caso poderá haver conversão de capital industrial em capital de empréstimo.

Como já se indicou, $l_{e}^{\prime}$ torna-se irrelevante para, em confronto com a taxa de juros, determinar o ponto a partir do qual os investimentos produtivos desviam-se para o setor financeiro. Em seu lugar comparece $l_{e p}^{\prime}$. Torna-se, portanto, de interesse determinar o valor da taxa de juros acima do qual $j^{\prime}>l_{e p}^{\prime}$. Em outras palavras, devese determinar o valor de $j^{\prime}$ em que $j^{\prime}=l_{e p}^{\prime}$. Parte-se da fórmula (5). Supondo $p^{\prime}$ inalterado, o aumento da taxa de juros reflete-se na redução do seu complemento, $l_{e}^{\prime}$, de modo que $l_{e p}^{\prime}$ cai. O valor de $j^{\prime}$ em que $j^{\prime}=l_{e p}^{\prime}$ é dado pela fórmula (5a), igualando-a a $j^{\prime}$ :

$$
j^{\prime}=\frac{\overline{l^{\prime}}-j^{\prime}}{p^{\prime}} \quad \therefore \quad p^{\prime} j^{\prime}=\bar{l}^{\prime}-j^{\prime} \quad \therefore \quad j^{\prime}=\frac{\overline{l^{\prime}}}{p^{\prime}+1}
$$

ou seja, $l_{e p}^{\prime}$ iguala-se a $j^{\prime}$ quando o valor de $j^{\prime}=\frac{\overline{l^{\prime}}}{p^{\prime}+1}$. A taxas de juros superiores, a taxa de lucro do empresário sobre o capital próprio é menor que a taxa de juros. Portanto, a partir deste ponto, poder-se-ia esperar uma tendência de migração de capitais dos investimentos produtivos para os financeiros. Note-se que este valor de $j^{\prime}$ como limite só é válido para um valor dado de $p^{\prime}$, que é o grau de endividamento de um capitalista ou de um ramo da produção. A redução de $p^{\prime}$, isto é, o aumento do grau de endividamento, eleva $l_{e p}^{\prime}$ à taxa de juros dada. Ou seja, quanto maior o grau de endividamento, maior é $l_{e p}^{\prime}$ e mais elevada, portanto, é a taxa de juros necessária para ultrapassar $l_{e p}^{\prime}$. Isto pode ser ilustrado com um exemplo hipotético simples: seja $\bar{l}^{\prime}=0,2$ e $p^{\prime}=0,8$. Aplicando a fórmula (7) encontra-se a taxa de juros que iguala $l_{e p}^{\prime}: j^{\prime}=0,2 / 1,8=0,11$. Para confirmar a validade deste resultado, aplica-se $j^{\prime}=0,11$ à fórmula (5a) e obtém-se: $l_{e p}^{\prime}=(0,2-0,11) / 0,8=0,11$. Portanto, à taxa de

fatores que podem funcionar como amortecedores, podendo-se citar as exigências de garantias crescentes, a manutenção de saldos médios mínimos etc. (JAFFEE, p. 539). Os efeitos de tais fatores, porém, a fim de manter a coerência com a presente análise, teriam de ser examinados metodicamente e seguindo o referencial teórico marxista. 
juros de 11\%, esta se iguala à taxa de lucro do empresário sobre o capital próprio. A taxas de juros maiores, $l_{e p}^{\prime}$ será menor que a taxa de juros. No presente exemplo, se a taxa de juros se elevasse a $0,12, l_{e p}^{\prime}=(0,2-0,12) / 0,8=0,10$, isto é, $l_{e p}^{\prime}$ seria menor que $j^{\prime}$.

\section{A Taxa de Lucro do Empresário sobre o Capital Próprio e a Taxa Média de Lucro}

Vimos acima, ao analisar o exemplo de Hilferding, que $l_{e p}^{\prime}$ pode ser superior à taxa média de lucro, $\bar{l}^{\prime}$. Isto significa que, com o desenvolvimento do sistema de crédito, a taxa média de lucro deixa de ser o limite máximo ao qual o capitalista industrial pode aspirar, à medida que $j^{\prime}$ se contrai. Com o crédito, o capitalista pode aspirar a uma rentabilidade superior à taxa média de lucro, expressa na taxa de lucro do empresário sobre o capital próprio. Em que condições pode isto ocorrer? Em um momento qualquer as principais categorias do lucro médio estão dadas: $\bar{l}^{\prime}, j^{\prime}$ e $l_{e}^{\prime}$.

Por outro lado, $l_{e p}^{\prime}$ é uma derivação das categorias principais com base na variação da composição própria/emprestada de cada capital ou de um ramo de produção, expressa por $p^{\prime}$. É do valor de $p^{\prime}$ que depende, portanto, a relação entre $l_{e p}^{\prime}$ e $\overline{l^{\prime}}$, ou seja, há uma faixa de valores de $p^{\prime}$ (mantendo-se inalteradas as demais categorias do lucro médio), para a qual $l_{e p}^{\prime} \geq \overline{l^{\prime}}$. Para encontrar este valor, basta substituir $l_{e p}^{\prime}$, nesta fórmula, pela sua expressão em (5), com o que se obtém:

$\frac{l_{e}^{\prime}}{p^{\prime}} \geq \bar{l}^{\prime}$, donde se segue que: $p^{\prime} \leq \frac{l_{e}^{\prime}}{\bar{l}^{\prime}}$, ou seja, para que $l_{e p}^{\prime} \geq \overline{l^{\prime}}$, é preciso que a proporção de capital próprio $\left(p^{\prime}\right)$ seja igual ou menor que a proporção de $l_{e}^{\prime}$ em $\bar{l}^{\prime}$.

Por exemplo, se $l_{e}^{\prime}=0,7 \bar{l}^{\prime}, l_{e p}^{\prime}$ será superior a $\bar{l}^{\prime}$ se $p^{\prime}<0,7$, ou seja, se $\mathrm{C}_{p}<0,7 \mathrm{C}$, isto é, se o capital próprio for menor que $70 \%$ do capital total. Disto se segue que, quanto maior for $j^{\prime}$, menor será $\frac{l_{e}^{\prime}}{\overline{l^{\prime}}}$, portanto menor terá de ser $p^{\prime}$ para que $l_{e p}^{\prime}$ supere $\bar{l}^{\prime}$. Como $p^{\prime}$ menor equivale a grau de endividamento maior, a condição de que $p^{\prime}\left\langle\frac{l_{e}^{\prime}}{\overline{l^{\prime}}}\right.$ será cada vez mais difícil de ser cumprida, à medida que a taxa de juros aumenta. Como os capitais menores encontram maior dificuldade para elevar o seu grau de endividamento, as suas condições de competitividade pioram em relação aos capitais maiores, à medida que a taxa de juros se eleva. 


\section{Variação da Taxa Média de Lucro}

Até este momento supôs-se constante a taxa média de lucro, de modo que o lucro do empresário dependia apenas do nível da taxa de juros. Mas a taxa média de lucro também varia, de modo que a taxa de lucro do empresário depende não só do nível da taxa de juros, mas também do nível da taxa média de lucro (OC, III/l, p. 269-70). A relação entre os movimentos destes três elementos apresenta certa complexidade, cuja análise não é objetivo deste artigo, mas que pode ser ilustrada pelo seu movimento ao longo do ciclo industrial. A taxa média de lucro e a taxa de juros apresentam movimentos característicos neste ciclo. Após permanecer baixa durante a estagnação, a taxa de juros tende a elevar-se à medida que o ciclo industrial ingressa e avança na fase da prosperidade, o que deveria fazer com que $l_{e}^{\prime}$ caísse.

No entanto, a taxa média de lucro também se eleva nesta fase, de modo que a elevação de $j^{\prime}$ não é seguida necessariamente pela redução de $l_{e}^{\prime}$. Por outro lado, o aumento de $j^{\prime}$ reflete o aumento da demanda de capital de empréstimo em relação à oferta, o que significa que o grau de endividamento deve estar aumentando, de modo que $p^{\prime}$ tende a se reduzir. Consequentemente é plausível sugerir que $l_{e p}^{\prime}$ está também em elevação na fase de prosperidade, pelo menos até um ponto avançado desta, lembrando que $l_{e p}^{\prime}$ varia nos capitais individuais, segundo o grau de endividamento de cada um. A variação efetiva de $l_{e p}^{\prime}$ depende da combinação das velocidades relativas de crescimento de $\bar{l}^{\prime}$ e de $j^{\prime}$, por um lado, e de redução de $l_{e}^{\prime}$, por outro.

O efeito do aumento da taxa de juros, por exemplo, tende a ser muito pequeno no início da prosperidade, pois se inicia a partir de uma base diminuta. Se, por exemplo, neste momento $\bar{l}^{\prime}=20 \%, j^{\prime}=2 \%$, e se $j^{\prime}$ se eleva em 50\%, passando para 3\%, $l_{e}^{\prime}$ cairá de $18 \%$ para $17 \%$, isto é, uma queda de apenas $5,5 \%$. Bastaria, portanto, que a taxa média de lucro aumentasse para $21 \%$, ou seja, uma variação de apenas $5 \%$, para anular o efeito do aumento de $50 \%$ da taxa de juros sobre a taxa de lucro do empresário.

\section{A Taxa de Ganho do Empresário sobre o Capital Próprio}

Uma extensão desta análise conduz a uma conclusão ainda mais desconcertante em relação ao senso comum econômico. A extensão sugerida consiste em examinar melhor o efeito sobre o rendimento obtido pelo capitalista industrial, do juro sobre 
o capital próprio. Segundo a proposição de Marx e sua ilustração por Hilferding, a contabilidade empresarial registra separadamente os dois rendimentos sobre o capital total: o juro e o lucro do empresário. Mas ambos são rendimentos auferidos pelo capitalista industrial. O registro dos dois rendimentos é uma consequência necessária da divisão qualitativa do lucro médio em juro e lucro do empresário, uma vez que o lucro médio, que é a soma dos dois, é o valor da mais-valia obtida por cada capitalista com base na taxa média de lucro. Consequentemente, a parte do lucro médio representada pelo juro deve incidir necessariamente sobre as duas partes do capital total, a própria e a emprestada, caso contrário uma parte do lucro médio efetivamente obtido ficaria sem registro. No entanto, o registro contábil em separado não altera o fato de que o capitalista industrial obtém objetivamente, do lucro médio que produz, toda a diferença entre o seu total e o que paga à conta de juros sobre empréstimos, isto é, $\bar{l}-j^{\prime} C_{e}$, que pode ser escrita do seguinte modo, com base em (3a):

$$
\bar{l}-j_{e}=l_{e}+j_{p}
$$

Pode-se, portanto, somar as duas partes do lucro médio que cabem ao capitalista industrial sob o nome de ganho do empresário, simbolizado por $g_{e}^{\prime}$, expressando-o da seguinte maneira:

$$
\begin{aligned}
& g_{e}=l_{e}+j_{p} \text {, ou na forma explícita: } \\
& g_{e}=l_{e}^{\prime} C+j^{\prime} C_{p}
\end{aligned}
$$

O valor do ganho do empresário, sob o ponto de vista do capitalista, é um rendimento resultante do investimento do seu capital próprio, mesmo que auxiliado por empréstimos. $^{22}$ Pode-se, portanto, sugerir o cálculo de uma taxa de ganho do empresário sobre o capital próprio, representada por $g_{e}^{\prime}$, que seria então:

$$
g_{e}^{\prime}=\frac{g_{e}}{C_{p}}
$$

22 “... o produto propriamente dito, específico, do capital é a mais-valia, ou mais precisamente, o lucro. Porém, para o capitalista que trabalha com capital emprestado não é o lucro, mas o lucro menos o juro, a parte do lucro que lhe resta depois de pagar o juro. Essa parte do lucro aparecelhe, pois, necessariamente como produto do capital à medida que este funciona; e assim é realmente para ele, pois somente representa o capital em funcionamento" (OC, III/1, p. 279). 
substituindo $g_{e}$ por (8):

$$
\begin{aligned}
& g_{e}^{\prime}=\frac{\left(l_{e}^{\prime} C+j^{\prime} C_{p}\right)}{C_{p}}, \text { ou } g_{e}^{\prime}=\left(\frac{l_{e}^{\prime} C}{C_{p}}\right)+j^{\prime} \\
& \therefore g_{e}^{\prime}=l_{e p}^{\prime}+j^{\prime}
\end{aligned}
$$

Duas desconcertantes conclusões retiram-se da fórmula (10). A primeira, é que a taxa de ganho do empresário que recorre ao crédito jamais cairá abaixo da taxa média de lucro. Isto decorre imediatamente do já exposto: como $l_{e p}^{\prime}>l_{e}^{\prime}$ sempre, segue-se que também $\left(l_{e p}^{\prime}+j^{\prime}\right)>\left(l_{e}^{\prime}+j^{\prime}\right)$ sempre, lembrando que $l_{e}^{\prime}+j^{\prime}=\overline{l^{\prime}}$.

Portanto, sempre se verificará que $g_{e}^{\prime}>\overline{l^{\prime}}$, para todos os capitalistas que recorram a empréstimos para complementarem o capital próprio. Também neste caso verificase que $g_{e}^{\prime}$ será reduzido caso o capitalista reduza o seu apelo ao crédito como reação à elevação de $j^{\prime}$. Este resultado é intuitivo: após o aumento da taxa de juros, no cálculo de $g_{e}^{\prime}$, segundo a fórmula (9), a redução do capital emprestado causaria a redução de $l_{e p}^{\prime}\left(=\frac{l_{e}^{\prime} C}{C_{p}}\right)$, devido ao aumento do capital próprio, no denominador, e à redução de $l_{e}^{\prime} C$, uma vez que $l_{e}^{\prime}$ se contrai devido ao aumento de $j^{\prime}$. A segunda conclusão é que $g_{e}^{\prime}$ será sempre maior que a $j^{\prime}$, uma vez que $g_{e}^{\prime}$ é a soma de $j^{\prime}$ mais $l_{e p}^{\prime}$.

Este resultado implica que, com crédito generalizado na economia, seria nula a possibilidade de que a taxa de juros concorresse com o capital industrial, uma vez que $g_{e}^{\prime}$ é sempre superior a $j^{\prime}$ por uma margem igual a $l_{e p}^{\prime}$. Resulta também desta análise que os capitalistas industriais e comerciais que não recorrem ao crédito encontram-se, em todas as circunstâncias, em situação pior, na concorrência, que os que recorrem regularmente ao crédito, pois as taxas de ganho destes excederão sempre as dos primeiros. Esta é uma indicação extremamente importante sobre o extraordinário papel representado pelo desenvolvimento do sistema de crédito no capitalismo. 


\section{Conclusões}

As principais conclusões, indicadas ao longo da exposição, podem ser assim sintetizadas:

1) Com a difusão do crédito, e a consequente divisão do lucro médio em lucro do empresário e juros, deve-se distinguir a rentabilidade teórica do capital industrial, que é a taxa média de lucro, da rentabilidade real do capitalista industrial;

2) Embora o lucro médio se divida em lucro do empresário e juros, a taxa de lucro do empresário não constitui medida da rentabilidade do capitalista industrial, mas apenas do rendimento da função produtiva do capital industrial. No artigo propõese uma medida adequada da rentabilidade do capitalista industrial, que é a taxa de lucro do empresário sobre o capital próprio;

3) Demonstra-se que a taxa de lucro do empresário sobre o capital próprio depende da taxa de juros e de um novo fator decorrente da difusão do crédito, que é o grau de endividamento do capitalista industrial;

4) Graças ao crédito, o capitalista industrial liberta-se da limitação da sua rentabilidade à taxa média de lucro, convertendo-se o crédito em verdadeira alavanca da acumulação;

5) Propõe-se finalmente uma medida do rendimento global obtido pelo capitalista industrial: a taxa de ganho do empresário sobre o capital próprio. Medido por esta taxa, mostra-se que o rendimento do capitalista industrial que recorre ao crédito é sempre superior à própria taxa média de lucro;

6) Com base nestas conclusões, pode-se afirmar que a extensão das implicações da divisão do lucro médio, sugeridas por Hilferding com base nas indicações de Marx, permitiu revelar novos ângulos do papel do sistema de crédito como potencializador do processo de acumulação. A análise realizada estende e reforça a indicação de Marx, retomada e parcialmente ampliada por Hilferding, no sentido de que a utilização do crédito, por capitalistas industriais e comerciais, constitui uma vantagem, e não uma desvantagem ou um comprometimento temporário indesejável, na concorrência, para os que o utilizam, em relação aos que trabalham apenas com capital próprio ou que apresentam menores graus de endividamento. 


\section{Referências}

FRIEDMAN, B.M.; NEWMAN, P.; MILGATE, M.; EATWELL, J. (Eds.). Capital, credit and money markets. The New Palgrave Dictionary of Money and Finance. Vol. 1, London: Macmillan, p. 276-283, 1994.

GERMER, C.M. Dinheiro, capital e dinheiro de crédito - o dinheiro segundo Marx. Unicamp, Campinas. Tese de Doutoramento. Mimeo, 1995.

GITMAN, L.J. Princípios de administração financeira. $12^{\mathrm{a}}$ ed. São Paulo, Pearson Prentice Hall, 800 p., 2010.

HILFERDING, R. Das Finanzkapital. Band 1, Frankfurt am Main: Europäische Verlagsanstalt, 513p., 1973.

ITOH, M.; LAPAVITSAS, C. Political economy of money and finance. London: Macmillan, 301p., 1999.

JAFFEE, D.M.; NEWMAN, P.; MILGATE, M.; EATWELL, J. (Eds.). Credit rationing. The New Palgrave Dictionary of Money and Finance. Vol. 1, London: Macmillan, p. 539-541, 1994.

KALECKI, M. Teoria da Dinâmica Econômica; Ensaio sobre as mudanças cíclicas e a longo prazo da economia capitalista. In: KEYNES, J.M. et al. Ensaios Econômicos. São Paulo: Abril Cultural, p. 55-207, 1976.

LIANOS, T.P. Marx on the rate of interest. Review of Radical Political Economics, Atlanta, v.19, n. 3, p. 34-55, Fall 1987.

MARX, K. Zur Kritik der Politischen Ökonomie (Manuskript 1861/63): (Theorien über den Mehrwert), [Teorias da mais-valia, Final]. Text - Teil 4. Berlin: Dietz Verlag, p. 1203-1539, 1979.

MARX, K. O Capital: crítica da economia política. Vol. I/1. São Paulo: Abril Cultural. 301 p., 1983.

MARX, K. O Capital: crítica da economia política. Vol. I/2. São Paulo: Abril Cultural. 1984. 306 p.

MARX, K. O Capital: crítica da economia política. Vol. III/1. São Paulo: Abril Cultural. 353 p. 1984. MARX, K. O Capital: crítica da economia política. Vol. III/2. São Paulo: Abril Cultural. 336 p., 1985.

MARX, K. Capital. Vol. 3, I. Edited by Frederick Engels. New York: International Publishers, 1967.

MAYER, T.; DUESENBERRY, J.S.; ALIBER, R.Z. Moedas bancos e a economia. $4^{\text {a }}$. Ed. americana. Rio de Janeiro: Campus. 681 p., 1993.

PANICO, C. Interest and profit in the theories of value and distribution. New York: St. Martin's Press, 229 p., 1988.

ROSS, S.A.; WESTERIELD, R.W.; JAFFE, J.F. Administração financeira. São Paulo: Atlas, 698 p., 1995. 